Kalpa Publications in Engineering
Volume 1, 2017, Pages 193-199
ICRISET2017. International Conference on Re-
search and Innovations in Science, Engineering
\&Technology. Selected Papers in Engineering $\quad$ Kalpel

\title{
Revisiting AC bridges: A Novel Method to Measure Domestic Capacitors Using Simple Techniques
}

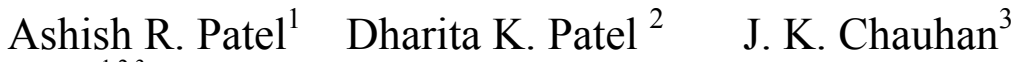 \\ ${ }^{1,2,3}$ Assistant Professor, Electrical Engineering Department \\ BVM Engineering College, Vallabh Vidyanagar, Gujarat, India \\ ashish.patel@bvmengineering.ac.in, dkpatel@bvmengineering.ac.in, \\ jkchauhan abvmengineering. ac. in
}

\begin{abstract}
DC and AC bridges have been used in abundance for a long period of time for the component measurements as well as other parameters measurements. AC bridges are principally used for the determinations of component values and the associated parameters namely the self-inductance, mutual inductance, capacitance etc. In this paper the authors have presented a novel method using latest computing and analysis tools to investigate the capacitor ageing of a popular capacitor used in day to day life using a nonconventional AC bridge like circuit.

Keywords-Unknown capacitors, AC bridges, DC bridges, Detector, Capacitor ageing
\end{abstract}

\footnotetext{
Abbreviations:

$\mathrm{V}$ : Applied Voltage to the circuit

$\mathrm{f}$ : The working frequency

r: The loss resistance of the choke coil

$\mathrm{X}_{1}$ : Inductive reactance of the choke coil at working frequency

$\mathrm{Xc}$ : Capacitive reactance of capacitor at working frequency

$\mathrm{R}$ : Variable balancing resistor

$\mathrm{Z}_{\mathrm{D}}$ : Impedance of the detector

I1, I2, I3: The loop currents used for the circuit analysis as shown
} 


\section{Introduction}

The role of capacitors in the world of electrical components is like a moon amongst stars. Even in the explicit or implicit forms or either a subtle or a micro scale, it is found very analogous to the existence of the ruling energy of the universe.

A large number of capacitors exists in society in various forms of applications. One of the most common and useful application is found even in Layman's home as a ceiling fan capacitor. It has a great influence on the performance of the ceiling fan as regards the speed as well as the energy consumption. In most of the cases the technicians or wireman or the electrician have the thumb rule impression of this capacitor being week when they are reported a fan running slower than the desired speed. Therefore, under the misconception in most of the cases, they feel it as the capacitor.

\section{Historical Background}

AC bridges have been designed, developed and studied over a long period of time. There is accumulation of a large quantum of literature in this connection [1], [2], [3], [4]. This bridges have been analyzed and studied and various useful applications have been devised for the measurement of various electrical parameters. The popular names in this connection are Anderson's bridge, D-sauty bridge, Wien bridge, Schering bridge etc [1], [8], [9]. They work on the principle of null basis. Very interestingly and fascinatingly the circuit used in this paper is not in a classical AC bridge form, but it also uses the zero-voltage principle across a detector for the measurement purpose of a capacitor. The original problem statement found in popular literature is described as follows:

A T network has series arm $\mathrm{AB}$ and BD. Each having a coil of $3 \mu \mathrm{H}$ and a loss resistance of $6 \Omega$ at $12 \mathrm{Mc} / \mathrm{s}$. The shunt arm BE is of a variable resistor $\mathrm{R}$ and the series arms are bridged by a calibrated variable capacitor $\mathrm{C}$ connected between $\mathrm{A}$ and $\mathrm{D}$. A voltage at $12 \mathrm{Mc} / \mathrm{s}$ is applied between $\mathrm{A}$ and $\mathrm{E}$.

Show that there is one combination $\mathrm{R}$ and $\mathrm{C}$ for which no voltage appears between $\mathrm{D}$ and $\mathrm{E}$ and evaluate these two components.

An unknown capacitance connected between $\mathrm{A}$ and $\mathrm{D}$ can be measured by noting the change in $\mathrm{C}$ required to restore the null condition. Explain the advantages of these method.[London university, Electrical Measurements].

The above historic problem is already available in the famous book on "Electrical Measurements and Instrumentation" [1]. The problem is presented as an exercise problem and is really interesting and also challenging from the angle of its solution. The classical solution made available by the author is subject to the availability of the computing tolls of that time and the associate accuracy. It was analytically solved and simulate using the tools available as on today. For the solution of the circuit as described above, the loop current method is chosen from the angle of intrinsic wisdom.

MATLAB ${ }^{\circledR}$ is the world famous and popular software for simulation and solution of variety of problems in engineering fields. The strong library of sources and components are the most favorable features of MATLAB ${ }^{\circledR}$ with a simple procedure to simulate a problem of electrical engineering and therefore here too was found to be worth and suitable [11]. 


\section{Case Study on a Few selected Capacitors}

\subsection{Problem Description}

As shown in Fig 1. A T-network has series arms AB and BD each having a coil of $3 \mu$ Henry and a loss resistance of $6 \Omega$ at 12 Mega Cycles per second is applied. The shunt arm BE is of variable resistor $\mathrm{R}$ and the series arms are bridged by a calibrated variable capacitor $\mathrm{C}$ connected between $\mathrm{A}$ and $\mathrm{D}$. Show that there is one combination of $\mathrm{R}$ and $\mathrm{C}$ for which no voltage appears between $\mathrm{D}$ and $\mathrm{E}$. And evaluate these two voltages. An unknown capacitance connected between A and D can be measured by noting the change in $\mathrm{C}$ required to restore the null conditions.

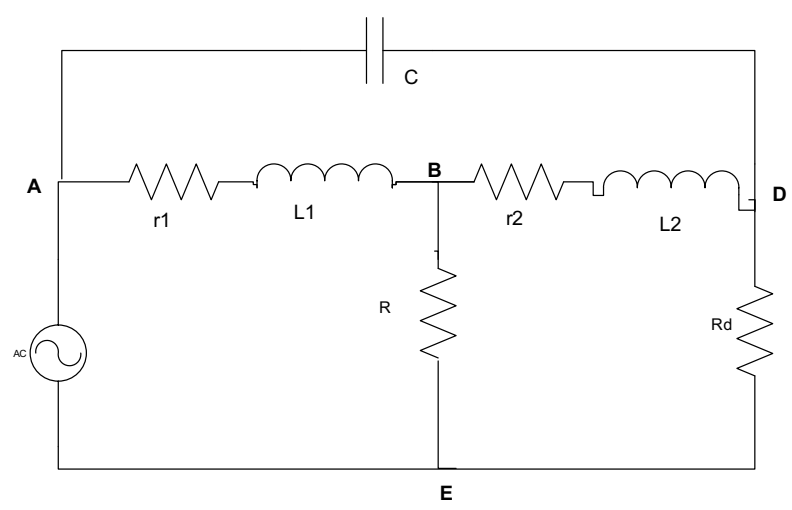

Figure 1: Circuit diagram

The loop current equations for the three loops can be written as follows:

$$
\begin{aligned}
& \left(r+R+j X_{1}\right) I_{1}-R_{2}-\left(r+j X_{1}\right) I_{3}=V \\
& -R I_{1}+\left(r+R+R d+j X_{1}\right) I_{2}-\left(r+j X_{1}\right) I_{3}=0 \\
& -\left(r+j X_{1}\right) I_{1}-\left(r+j X_{1}\right) I_{2}+\left(2 r+j 2 X_{1}-j X c\right) I_{3}=0
\end{aligned}
$$

Voltage across the detector $\mathrm{V}_{\mathrm{D}}=\mathrm{I}_{2} * \mathrm{R}_{\mathrm{d}}$

Using Krammer's Rule,

Using Krammer's Rule,

$$
\begin{array}{ccc}
r+R+j X l & V & -(r+j X l) \\
-R & 0 & -(r+j X l) \\
-(r+j X l) & 0 & 2 r+j 2 X l-X c
\end{array}
$$

$\mathrm{I}_{2}=$

$$
\begin{array}{ccc}
r+R+j X l & -R & -(r+j X l) \\
-R & r+R+R d+j X l & -(r+j X l) \\
-(r+j X l) & -(r+j X l) & 2 r+j 2 X l-j X c
\end{array}
$$


It is noted that at the working conditions, denominator determinant is non-zero. Now as per the solution requirements, $V_{D}=0$, therefore, $I_{2} * R_{d}=0$, therefore $I_{2}=0$.

Thus, on solving for $\mathrm{I}_{2}=0$, we have two independent equations,

$\mathrm{R}=\left(\mathrm{X}_{1}^{2}-\mathrm{r}^{2}\right) / 2 \mathrm{r}$

And $X c=\left[4 r^{2} X_{1}+2 X_{1}\left(X_{1}^{2}-r^{2}\right)\right] /\left(X_{1}^{2}-r^{2}\right)$

Substituting the given values, we have

$\mathrm{C}=27.88$ picofarad and $\mathrm{R}=4250 \Omega$.

$\mathrm{X}_{\mathrm{l}}=226.30 \Omega$

$\mathrm{R}=4264 \Omega$

$\mathrm{Xc}=-451.9 \Omega$

$\mathrm{C}=29.3$ picofarad

It is very interesting to note from the expressions for $\mathrm{R}$ and $\mathrm{C}$ that these expressions do not involve $R_{d}$. Thus the impedance of the detector does not affect the component values at all. In fact this is one of the most desirable implicit feature to implement a simple student class digital multi-meter for the voltage measurement or minimum voltage detection.

The solution was found satisfactory on all three tests.

The authors have proposed a scheme where a known value of capacitance is compared with the easily available choke coils, resistors and the ac source. Later on, the capacitor on test can be compared with the standard values and the percentage deterioration can be estimated. The proposed model is not luxurious, nor glamorous in its appearance but it is very simple and user friendly. In addition to that it provides a quick and scientific judgment on a readable scale and indicator.

\subsection{MATLAB Simulation}

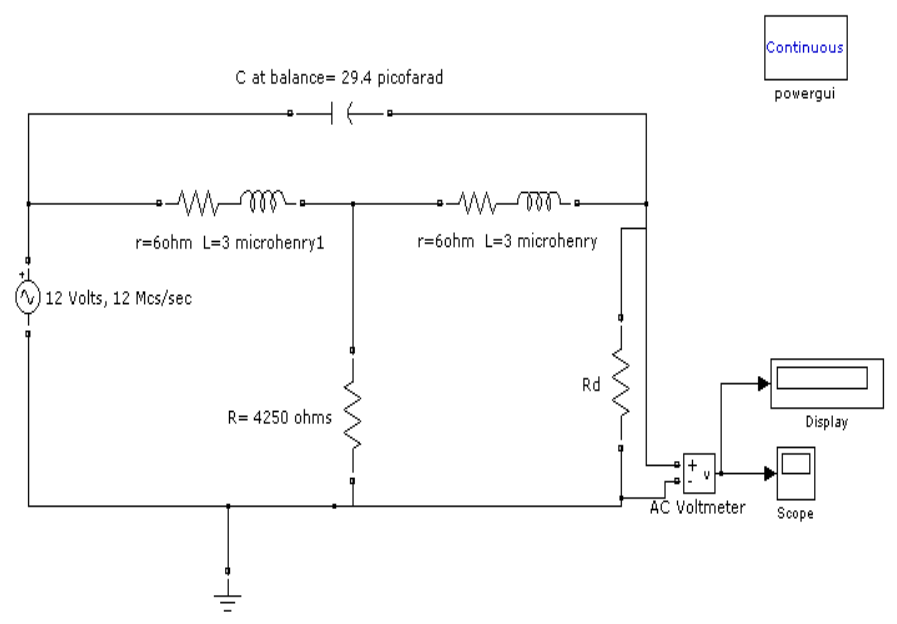

Figure 2: MATLAB Simulation of circuit

Various learned researchers and scholars have used MATLAB ${ }^{\circledR}$ Graphics to solve the complex geometry of the Engineering fields and the same was used here also. [5], [6] The results were found to be satisfactorily matching. 


\subsection{Experimental setup}

Fig 3. Shows the experimental arrangement of the circuit shown in Fig 1.

Two non-identical coke coils were taken as inductances.

A bulb was taken as a detector

The inductive coils chosen here are simply the choke coils used in fluorescent tube light circuits (and the rheostat is chosen as a variable calibrating resistance for the time being. Similarly, the detector circuit is formed by choosing a push button and a simple lamp as it can quickly detect the presence of the voltage across the detector. Our objective is to make the determination of the ceiling fan capacitor value and to a crude extent the leakage resistance. The circuit is energized using the easily available 230 volts, 50 hertz supply and an auto-transformer.

As per the requirements of measurements, identical coils are preferred. [1] The identically of these coils were tested using the principles of ac series circuits quickly and comfortably.[1],[4]

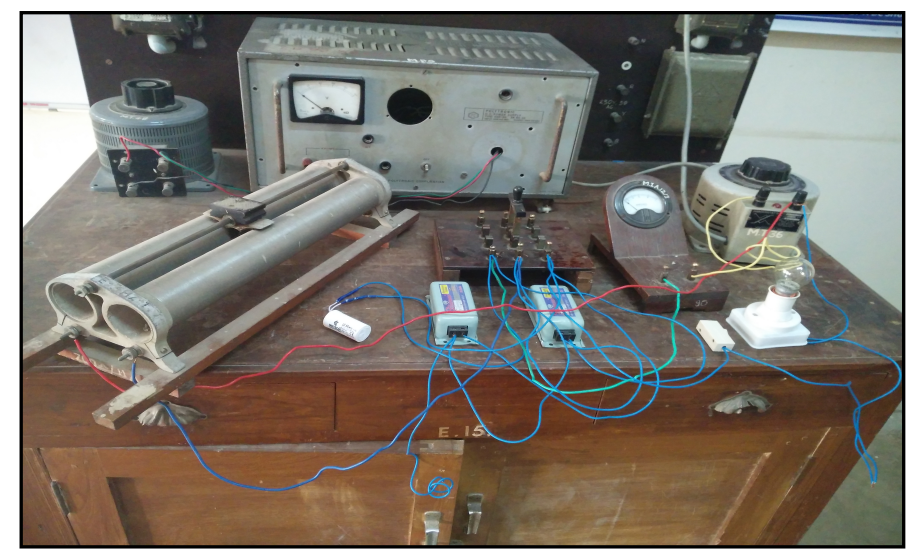

Figure 3: Experimental setup

\section{Results and Findings}

Our objective is to obtain preferably the per unit or percentage weakness in a proposed capacitor in comparison. A voltage across a detector was used as a measure for the proposed weakening effect in a capacitor and was provided in the form of a chart.

Fig. 3 shows a laboratory setup devised for the method discussed here. All the readings mentioned in Table I and II are obtained using the setup used for the experiment as shown in figure 3.

The popular three voltmeter method was used to determine the parameters of the capacitors under test and the readings were obtained using readily available instruments (student grade DMM). The readings are tabulated as per the following table. Very interestingly the method provided the readings and results very close to the theoretical agreements. Fortunately, a brand-new capacitor and the old capacitors of different manufacturers were available and therefore, there was a much better ambience to perform the experimental procedures. 


\begin{tabular}{|c|c|c|c|c|c|}
\hline Sr. no. & Capacitor & $\begin{array}{l}\mathrm{R} \\
\text { in ohms }\end{array}$ & $\begin{array}{c}\mathrm{V}_{1} \\
\text { in volts }\end{array}$ & $\begin{array}{c}\mathrm{V}_{2} \\
\text { in volts }\end{array}$ & $\begin{array}{c}\mathrm{V}_{3} \\
\text { in volts }\end{array}$ \\
\hline \multirow{2}{*}{1.} & Fresh Brand new capacitor & 700 & 88 & 49 & 73 \\
\cline { 3 - 6 } & & 700 & 127 & 70 & 105 \\
\cline { 3 - 6 } & & 700 & 176 & 98 & 146 \\
\hline 2. & C1 ( Havells make) & 700 & 110 & 49 & 97 \\
\cline { 3 - 6 } & & 700 & 152 & 70 & 135 \\
\cline { 3 - 6 } & & 700 & 215 & 98 & 190 \\
\hline 3. & C2 (Usha make) & 700 & 123 & 49 & 112 \\
\cline { 3 - 6 } & & 700 & 173 & 70 & 158 \\
\cline { 3 - 6 } & & 700 & 240 & 98 & 220 \\
\hline 4. & C3 (Concap make) & 700 & 88 & 49 & 73 \\
\cline { 3 - 6 } & & 700 & 126 & 70 & 104 \\
\cline { 3 - 6 } & & 700 & 177 & 98 & 147 \\
\hline
\end{tabular}

Table 1: Experimental results

Summarily, it can be said that the voltage appearing across the detector (student grade DMM) is a direct measure of the capacitance under measurement to some scale.(!!!)

\begin{tabular}{|c|l|l|l|c|}
\hline Qty & $\begin{array}{l}\text { Fresh } \\
\text { Brand } \\
\text { capacitor }\end{array}$ & $\begin{array}{l}\text { C1 } \\
\text { ( Havells make) }\end{array}$ & $\begin{array}{l}\text { C2 } \\
\text { (Usha make) }\end{array}$ & $\begin{array}{c}\text { C3 } \\
\text { (Concap make) }\end{array}$ \\
\hline $\mathrm{P}$ (Watts) & 0.1457 & 0.3721 & 0.0464 & 0.1143 \\
\hline $\cos \Phi$ & 0.0139 & 0.0140 & 0.0029 & 0.110 \\
\hline $\mathrm{ZC} \mathrm{(Ohms)}$ & 1050 & 1357 & 1580 & 1040 \\
\hline $\mathrm{rc}(\mathrm{Ohms})$ & 14.57 & 18.98 & 4.64 & 11.43 \\
\hline $\mathrm{xc}(\mathrm{Ohms})$ & 1049.50 & 1356 & 1579.7 & 3.06 \\
\hline $\mathrm{C} \quad(\mathrm{micro}$ & 3.031 & 2.34 & 2.01 & \\
\hline Farad) & & & & \\
\hline
\end{tabular}

Table 2: Results of Experimentations

\section{Future Scope}

The aforesaid voltage described in findings can now be appropriately processed using more sophisticated circuits and components and a more user-friendly display can be designed and made available for the service to the society.

\section{Acknowledgment}

Our sincere thanks to BVM and CVM for inspiration and moral support. Heartily thanks to the organizers of ICRISET 2017 for providing the authors the opportunity to present this work. Thanks to the department faculty members for their interest and enthusiasm namely prof. Dr. B R Parekh, prof. A A Shaikh, Prof. Dr. N G Mishra.

Last but not the least, the most and hearty thanks for the family members for their patience and generosity to provide the ambience for work. 


\section{References}

[1] E. W. Golding \& Fredric Charles Widdis, Electrical Measurements and Measuring Instruments, London: Pitman Publishers., 1968.

[2] A. K. Sawhney, A Course in Electrical and Electronic Measurements and Instrumentation, Dhanpatrai \& Co., 19th Edition.

[3] M. E. Van Valkenburg, Network Analysis, Pearson Publications, 3rd Edition.

[4] Boris Kuznetsov, Bridge and Potentiometer Methods of Electrical Measurements, Moscow: Peace Publications, 1968.

[5] Dharita K Patel, J. K. Chauhan, A. R. Patel, Dr. N. G. Mishra, "Revisiting ZPF Method in Novel Computing Environment", IJRITCC, Vol. 04, Issue 04, pp. 787-791., April 2016.

[6] Dharita K Patel, J. K. Chauhan, Ashish R. Patel, N. G. Mishra, “A User Friendly Simulation for Transformer Vector Group”, IEEE International Conference CSNT 2012, ISBN:978-1-4673-1538-8, pp. 820-824.

[7] Hammam Soliman, Huai Wang, Frede Blaabjerg, "A review of the condition monitoring of capacitors in power electronic converters", IEEE Transactions on Industrial Applications, Vol. 52, Issue 06, Nov-Dec 2016., pp. 4976-4989.

[8] A. Campbell \& E. C. Childs, The Measurement of Inductance, Capacitance and Frequency

[9] W. L. Walton \& M. E. Pemberton, "A Direct Capacitance Aircraft Altimeter"Proceeding IEEE, Vol. 96, Part-2, page-7379.

[10] Goswami Tulsidas, "Shrimad RamCharit Manas", Gita Press, Gorakhpur.

[11] www.mathworks.com 